\title{
Occupational injuries of teachers and educational staff at special schools with multiple and severely handicapped children in Rhineland-Palatinate (Germany): results of a cross-sectional study
}

\author{
Matthias Claus ${ }^{1}$, Renate Kimbel ${ }^{2}$, Stephan Letzel ${ }^{1,2}$ and Dirk-Matthias $\operatorname{Rose}^{1}$ \\ ${ }^{1}$ Institute for Teachers' Health at the University Medical Center of the Johannes Gutenberg University of Mainz, \\ Germany and ${ }^{2}$ Institute of Occupational, Social, and Environmental Medicine at the University Medical Center of \\ the Johannes Gutenberg University of Mainz, Germany
}

\begin{abstract}
Occupational injuries of teachers and educational staff at special schools with multiple and severely handicapped children in RhinelandPalatinate (Germany): results of a cross-sectional study: Matthias CLAUS, et al. Institute for Teachers' Health at the University Medical Center of the Johannes Gutenberg University of Mainz, GermanyObjectives: The present study aimed to describe the prevalence, type, and influencing factors of occupational injuries of staff working at special schools with multiple and severely handicapped pupils in Southwestern Germany. Methods: This cross-sectional study was carried out between August 2010 and August 2012 at 13 special schools with focus on motoric and/or holistic development of handicapped pupils in RhinelandPalatinate (Germany). Participants were interviewed using a written questionnaire. Results: There were 395 participants (response proportion: $59.7 \%$ ) in our study, with 390 being eligible for statistical analysis. Respondents were on average 45 years old and mainly female $(86.9 \%)$. The 12-month injury prevalence was $16.9 \%$. Joint dislocations, sprains, and torn ligaments $(41.6 \%)$ were the main types of injuries. Pupils (59.8\%) and auxiliary equipment (12.2\%) were identified as the main causes of injury by the respondents. Multivariable logistic regression analysis showed that washing pupils (using auxiliary equipment) (aOR, 3.93; 95\% Cl, 1.66-9.31) and daily physical strain due to unexpected conduct of pupils (aOR, 3.70; 95\% CI, 1.20-11.37) were the main influencing factors for an occupational injury. Conclusions: Almost one in five persons suffered an occupational injury in the previous 12 months. Nursing
\end{abstract}

Received Sept 10, 2014; Accepted Jun 15, 2015

Published online in J-STAGE Jul 31, 2015

Correspondence to: M. Claus, Institute for Teachers' Health at the University Medical Center of the Johannes Gutenberg University of Mainz, Kupferbergterrasse 17-19, 55116 Mainz, Germany (e-mail: Matthias.claus@unimedizin-mainz.de) activities, including close contact with pupils, were identified as the most important factors for an injury. In order to prevent injuries at special schools, a multifaceted approach is necessary. This includes sufficient supply of auxiliary devices including proper technical maintenance. Furthermore, regular participation in training for manual handling of heavy loads and schooling on the technical use of auxiliary devices should be encouraged.

(J Occup Health 2015; 57: 465-473)

Key words: Germany, Injuries, Nursing, Special schools, Teachers, Workplace accidents

In Germany, recent estimates suggest that there were about 1.1 million workplace and commuting accidents in 2012 ${ }^{1}$. Occupational accidents not only have a negative impact on the health and economic well-being of the individual (disability, lost time) but also affect employers (loss of working hours, administration efforts) and all of society (economic losses) ${ }^{2}$. In order to identify possibilities for prevention, the occupation-specific background of these accidents must be investigated.

At special schools with multiple and severely handicapped pupils in Germany, work tasks are diverse and combine teaching with a variety of nursing tasks like lifting and transferring pupils, toilet assistance, and washing pupils. Accordingly, people working at these schools have different professional backgrounds, with teachers in a classical sense working together with educational staff like physiotherapists, ergotherapists, nurses, social educational workers, and others. Generally speaking, staff at special schools with multiple and severely handicapped pupils work at the interface between teaching and nursing. Thus, besides teacher-related tasks, staff at special schools have to 
deal with hard physical work (including heavy lifting and bending), the handling of assistive devices (e.g., lifters), and the often unpredictable behavior and unintentional violence of severely handicapped pupils.

To the best of the authors' knowledge, no studies on work-related injuries and/or accidents of staff working at special schools currently exist. Publications on occupational accidents and injuries of teachers in general are scarce and focus mainly on accidents during physical education, such as those of Goossens et al., Kovac et al., and Lemoyne et al. ${ }^{3-5)}$. However, since nursing care forms an integral part of the everyday work routine of staff at special schools, a closer look at research aiming at occupational injuries of nurses and/or health-care workers in general could be helpful. Recent studies on health-care workers suggest that nurses are at high risk of occupational accidents and injuries ${ }^{6-8)}$. In Germany, Nolting and colleagues (2002) observed a 12-month prevalence of occupational injuries in hospital nurses of $31.7 \%$ (including needle-stick injuries) ${ }^{9}$. Regarding major risk factors for the occurrence of occupational injuries in nurses, research almost unanimously regards nursing tasks requiring heavy physical work, such as lifting and transferring of patients ${ }^{10-13)}$, as crucial. In this context, the use of assistive devices, e.g., lifters, seems to have a protective effect ${ }^{10,14}$, although conflicting results exist ${ }^{11,15)}$. Further risk factors mentioned sporadically include psychological factors such as high levels of stress ${ }^{9)}$ or depression ${ }^{16)}$ and workplace characteristics such as working full time (longer exposition) and low professional experience ${ }^{9}$. Independent of profession, having an unhealthy lifestyle, being male ${ }^{16)}$ (more prone to risk behaviors), and being of younger age ${ }^{17)}$ (less experience at work) are important risk factors for occupational accidents.

However, there are no findings on occupational injuries and accidents in special schools, and results concerning accidents in health-care workers cannot be simply transferred to the context of special school teachers. Therefore, the present study aimed to describe the prevalence, type, and influencing factors of occupational injuries of staff working at special schools with multiple and severely handicapped pupils in Rhineland-Palatinate (Germany).

\section{Methods}

Study design

The method of data collection has already been described previously ${ }^{18)}$. Briefly, a cross-sectional study was carried out between August 2010 and August 2012 at 13 special schools focusing on motoric and/or holistic development of severely and multiple handicapped children in Rhineland-Palatinate (Germany). Data of teachers and educational staff were surveyed using written questionnaires. In addition, blood samples were collected and physical examinations were performed for all participants. The study was conducted by the Institute of Occupational, Social and Environmental Medicine and the Institute for Teachers' Health at the University Medical Center of the Johannes Gutenberg University of Mainz. The study was approved by the State Ministry of Rhineland-Palatinate for Education, Science, Further Education and Culture (MBWWK), the supervision and service administration body (ADD) in Trier, the main staff councils of the special schools for children with learning difficulties, the ethics committee of the medical association of the German State of RhinelandPalatinate, and the responsible principals and local staff councils.

\section{Questionnaire}

The data were surveyed using a medical history questionnaire with 84 questions regarding the topics sociodemographic background, professional qualification, state of health, and health-related behavior. Most questions in the questionnaire were developed by the Institute of Occupational, Social and Environmental Medicine. Further questions were adopted from the questionnaire of the GEDA study (Gesundheit in Deutschland aktuell) developed by the Robert Koch Institute $^{19)}$.

\section{Variable construction}

The dependent variable "occupational injury" was surveyed by the question "Have you suffered an occupational injury at your school during the last 12 months? - Yes / No / I don't know". Using this definition, we wanted to survey all kinds of injuries in the past year, independent of any medical attendances or official reporting requirements.

In order to obtain more specific information about which type of injury occurred, the respondents were asked to select one of the following categories (multiple answers permitted): "bone fracture", "concussion of the brain", "joint dislocation, sprain, torn ligament", "open wound, superficial injury, bruise", "hearing impairment", "burn", "internal injury", and "other". Furthermore, the respondents provided information on the cause of the injury using the following categories (multiple answers permitted): "pupil", "auxiliary equipment", "commuting accident", and "other (freetext option)". As a result of the free-text option, we set up two more categories, "physical education" and "personal negligence".

Regarding sociodemographic and other personal characteristics, we used information on age, sex, marital status, profession, time working per week, duration of professional activity at current workplace, total 
duration of working as a teacher/educational staff, smoking status, alcohol consumption, and body mass index (BMI). Profession was surveyed by asking whether respondents were employed as teachers or educational staff. The term "educational staff" is not clearly defined and is rather a collective name for all non-teachers working at special schools (e.g., physiotherapists, ergotherapists, and nurses).

Additionally, several variables relating to nursing tasks were included in our analyses. Teachers and educational staff were asked if they were involved in carrying, lifting, and transferring pupils, washing pupils, toilet assistance for pupils, changing pupils' diapers, (un-)dressing pupils, administration of drugs/food to pupils, and/or catheterization of pupils. If this was the case, respondents were asked to state if their school provides sufficient auxiliary equipment to perform the specific nursing task(s) or not. Furthermore, respondents were asked about the frequency of physical strain due to unexpected conduct of pupils using the following categories: "daily", "weekly", "monthly", "never/less than monthly". We subsequently summarized monthly, less than monthly, and never into one category.

\section{Statistical analyses}

All statistical analyses were carried out using Stata/ IC 12.1 (StataCorp LP, College Station, TX, USA). Absolute and relative frequencies were calculated for a general description of the study participants. In bivariate analyses, we applied Pearson's chi-squared test (in case of two categorical variables) or the MannWhitney $U$ test (in case of one continuous and one categorical variable) to test for associations between sociodemographic/nursing variables and occupational injury. Results were considered significant for $p<0.05$. We used a multivariable logistic regression analysis to identify factors that influenced whether $(=1)$ or not $(=0)$ participants suffered an occupational injury in the previous 12 months. Apart from age and sex, only variables significantly associated with injury status in bivariate analyses were entered into the multivariable regression model. The missing-indicator method was used to deal with existing missing values in the dataset.

\section{Results}

Altogether, 395 persons from 13 different schools participated in our study, corresponding to an overall response proportion of $59.7 \%$. Excluding five persons with missing information or the answer "I don't know" for the dependent variable, information on 390 persons could be analyzed. Of the 390 participants, $66(16.9 \%)$ stated that they had suffered at least one occupational injury in the twelve months preced- ing study participation. Table 1 shows some basic personal characteristics of the participants in total and stratified by injury status. The mean age of the study participants was 45 years (SD: 9.9), with the vast majority of respondents being female $(86.9 \%)$. More than two-thirds $(69.0 \%)$ worked as educational staff.

The prevalence of occupational injury was significantly higher $(p=0.013)$ for educational staff $(20.1 \%)$ compared with teachers $(9.9 \%)$. Regarding other personal characteristics, no significant differences were found regarding the dependent variable.

The number of injuries per person is displayed in Fig. 1.

Altogether, the participants suffered 89 injuries. The vast majority of persons suffered one $(69.7 \%)$ or two $(25.8 \%)$ occupational injuries.

The type of injuries are displayed in Fig. 2. The figure shows that more than one-third of the injuries were joint dislocations, sprains and torn ligaments (41.6\%), and this was also the case for open wounds, superficial injuries, and contusions (33.7\%).

Furthermore, bone fractures $(9.0 \%)$ and hearing impairments $(2.2 \%)$ were mentioned sporadically.

The causes of the injuries as stated by the respondents are shown in Fig. 3. The vast majority of injuries were caused by pupils (59.8\%), followed by auxiliary equipment (like lifters etc.; 12.2\%), physical education $(6.1 \%)$, and personal negligence $(6.1 \%)$.

Table 2 shows the distribution of nursing tasks in the study population, as well as the association between nursing tasks and workplace injuries. Regardless of the availability of auxiliary equipment, the vast majority of study participants were involved in nursing activities. Almost $90 \%$ of the respondents carried, lifted and transferred pupils (89.5\%), (un-)dressed pupils (88.7\%), and/or administered drugs/food to pupils $(83.6 \%)$. Slightly less than one-third $(26.4 \%)$ of the respondents were involved in the catheterization of pupils.

We found significant associations between carrying, lifting, and transferring pupils $(p=0.032)$, washing pupils $(p<0.001)$, administration of drugs/food to pupils $(p=0.013)$, physical strain due to unexpected conduct of pupils $(p<0.001)$, and the dependent variable. The prevalence of workplace injuries was highest for respondents involved in the washing of pupils with available auxiliary equipment $(26.1 \%)$ and for respondents who reported daily physical strain due to unexpected conduct of pupils $(23.8 \%)$.

Table 3 shows the results of the multivariable logistic regression analysis regarding factors that influenced whether or not participants suffered an occupational injury in the previous 12 months.

The results show that washing pupils with auxiliary equipment (aOR, 3.93; 95\% CI, 1.66-9.31) and daily 
Table 1. Personal characteristics of the sample, stratified by injury status $(n=390)$

\begin{tabular}{|c|c|c|c|c|c|c|}
\hline \multirow[b]{3}{*}{ Personal characteristics } & \multirow[b]{3}{*}{ Total $(\%)$} & \multicolumn{4}{|c|}{$\begin{array}{l}\text { Occupational injury/injuries in the } \\
\text { previous } 12 \text { months }\end{array}$} & \multirow[b]{3}{*}{$p$-value } \\
\hline & & \multicolumn{2}{|c|}{ Yes $(n=66)$} & \multicolumn{2}{|c|}{ No $(n=324)$} & \\
\hline & & $\mathrm{n}$ & $\%$ & $\mathrm{n}$ & $\%$ & \\
\hline Age (years) & $\begin{array}{l}\text { Mean: } 44.9 \\
\text { (SD: } 9.9)\end{array}$ & & & $\begin{array}{r}\mathrm{Me} \\
(\mathrm{SI}\end{array}$ & $\begin{array}{l}44.6 \\
.9)\end{array}$ & $0.168^{c}$ \\
\hline$<30$ & $36(9.2)$ & 5 & 13.9 & 31 & 86.1 & \\
\hline $30-39$ & $90(23.1)$ & 13 & 14.4 & 77 & 85.6 & \\
\hline $40-49$ & $111(28.5)$ & 17 & 15.3 & 94 & 84.7 & \\
\hline$\geq 50$ & $153(39.2)$ & 31 & 20.3 & 122 & 79.7 & \\
\hline Sex & & & & & & $0.882^{\mathrm{b}}$ \\
\hline Male & $51(13.1)$ & 9 & 17.7 & 42 & 82.4 & \\
\hline Female & $339(86.9)$ & 57 & 16.8 & 282 & 83.2 & \\
\hline Marital status ${ }^{\mathrm{a}}$ & & & & & & $0.668^{\mathrm{b}}$ \\
\hline Married & $247(63.3)$ & 41 & 16.6 & 206 & 83.4 & \\
\hline Single & $91(23.3)$ & 13 & 14.3 & 78 & 85.7 & \\
\hline Divorced & $44(11.3)$ & 10 & 22.7 & 34 & 77.3 & \\
\hline Widowed & $5(1.3)$ & 1 & 20.0 & 4 & 80.0 & \\
\hline Profession & & & & & & $0.013^{\mathrm{b}}$ \\
\hline Educational staff & $269(69.0)$ & 54 & 20.1 & 215 & 79.9 & \\
\hline Teacher & $121(31.0)$ & 12 & 9.9 & 109 & 90.1 & \\
\hline Time working per week ${ }^{\mathrm{a}}$ & & & & & & $0.111^{\mathrm{c}}$ \\
\hline $0-<20$ hours & $97(24.9)$ & 14 & 20.0 & 83 & 80.0 & \\
\hline $20-<30$ hours & $112(28.7)$ & 14 & 12.9 & 98 & 87.1 & \\
\hline $30-<40$ hours & $161(41.3)$ & 34 & 21.8 & 127 & 78.2 & \\
\hline $40+$ hours & $11(2.8)$ & 2 & 7.4 & 9 & 81.8 & \\
\hline Duration of professional activity at current workplace & & & & & & $0.365^{\mathrm{b}}$ \\
\hline$<10$ years & $179(45.9)$ & 28 & 15.6 & 151 & 84.4 & \\
\hline $10-<20$ years & $122(31.3)$ & 18 & 14.8 & 104 & 85.3 & \\
\hline $20-<30$ years & $50(12.8)$ & 11 & 22.0 & 39 & 78.0 & \\
\hline $30+$ years & $36(9.2)$ & 9 & 25.0 & 27 & 75.0 & \\
\hline Total duration of working as a teacher/educational staff & & & & & & $0.709^{\mathrm{b}}$ \\
\hline$<10$ years & $103(26.1)$ & 14 & 13.9 & 87 & 86.1 & \\
\hline $10-<20$ years & $115(29.1)$ & 18 & 15.8 & 96 & 84.2 & \\
\hline $20-<30$ years & $83(21.0)$ & 15 & 18.3 & 67 & 81.7 & \\
\hline $30+$ years & $87(22.0)$ & 17 & 19.8 & 69 & 80.2 & \\
\hline Smoking status & & & & & & $0.860^{\mathrm{b}}$ \\
\hline Current smoker & $80(20.5)$ & 15 & 18.8 & 65 & 81.3 & \\
\hline Quitted smoking & $117(30.0)$ & 19 & 16.2 & 98 & 83.8 & \\
\hline Never smoked & $192(49.2)$ & 31 & 16.2 & 161 & 83.9 & \\
\hline Alcohol consumption & & & & & & $0.822^{\mathrm{b}}$ \\
\hline$\geq 4$ times a week & $34(8.7)$ & 4 & 11.8 & 30 & 88.2 & \\
\hline 2-3 times a week & $95(24.4)$ & 15 & 15.8 & 80 & 84.2 & \\
\hline 2-4 times a month & $146(37.4)$ & 25 & 17.1 & 121 & 82.9 & \\
\hline sonce a month/never & $114(29.2)$ & 21 & 18.4 & 93 & 81.6 & \\
\hline BMI & & & & & & $0.113^{\mathrm{b}}$ \\
\hline Obesity (BMI $\geq 30)$ & $40(10.3)$ & 10 & 25.0 & 30 & 75.0 & \\
\hline Overweight $(25 \leq \mathrm{BMI}<30)$ & $95(24.4)$ & 20 & 21.1 & 75 & 79.0 & \\
\hline Normal weight $(\mathrm{BMI}<25)$ & $254(65.1)$ & 36 & 14.2 & 218 & 85.8 & \\
\hline
\end{tabular}

Percentages are relative to the total number of respondents per characteristics (row) except for those in brackets (column percentages). ${ }^{a}$ Missing values for marital status $(n=3)$, time working per week $(n=9)$, duration of professional activity at current workplace $(n=3)$, total duration of working as a teacher/educational staff $(n=7)$, smoking status $(n=1)$, alcohol con-

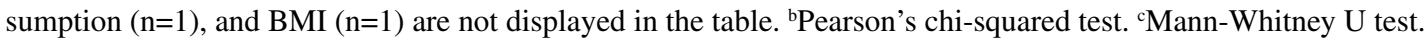




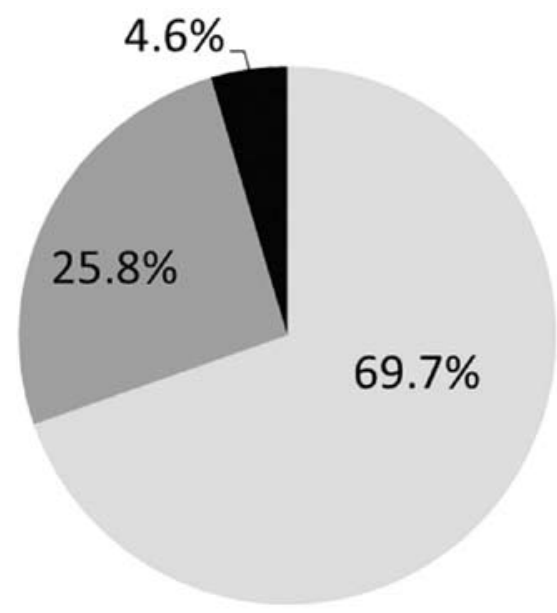

Fig. 1. Number of injuries per person in the sample $(n=66)$.

physical strain due to unexpected conduct of pupils (aOR, 3.70; 95\% CI, 1.20-11.37) are the main factors predicting an occupational injury of teachers and educational staff at special schools with multiple and severely handicapped children.

\section{Discussion}

\section{Main findings}

The aims of the present study were to describe the prevalence, type, and influencing factors of occupational injuries of staff working at special schools with multiple and severely handicapped pupils in Rhineland-Palatinate (Germany). We found a prevalence of occupational injuries of $16.9 \%$ in our sample. About one-third of the respondents suffered more than one injury. Bivariate analyses showed that the prevalence of injuries was significantly higher for educational staff compared with teachers and for respondents who were involved in nursing activities like carrying, lifting, transferring pupils, washing pupils, and administering drugs/food to pupils compared with participants who did not carry out these tasks. Furthermore, respondents who experience physical strain due to unexpected conduct of pupils on a daily basis had a significantly higher prevalence of occupational injuries compared with respondents who experienced such a conduct weekly or (less than) monthly. Accidents resulted predominantly in joint dislocations, sprains, and torn ligaments, as well as open wounds, superficial injuries, and contusions. The majority of injuries were caused by pupils, followed by auxiliary equipment.

The multivariable logistic regression analyses showed that washing pupils with auxiliary equipment and daily physical strain due to unexpected conduct of pupils were the main factors that influenced whether or not participants suffered an occupational injury in

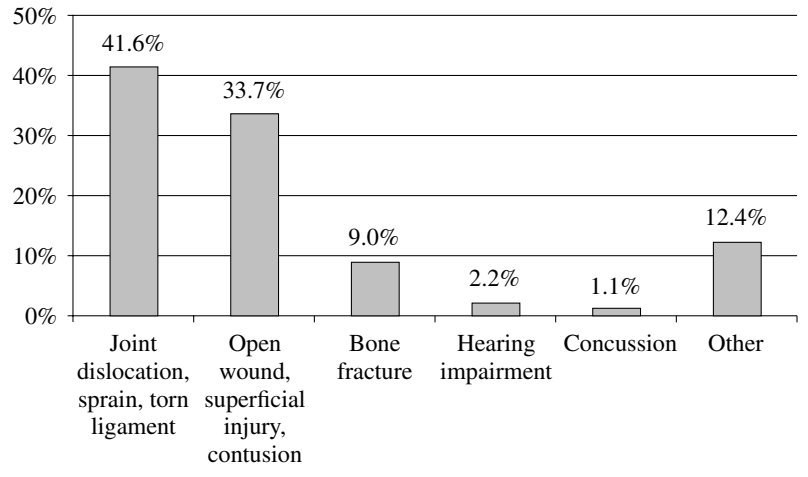

Fig. 2. Type of injury ( $n=89$ injuries; multiple answers allowed).

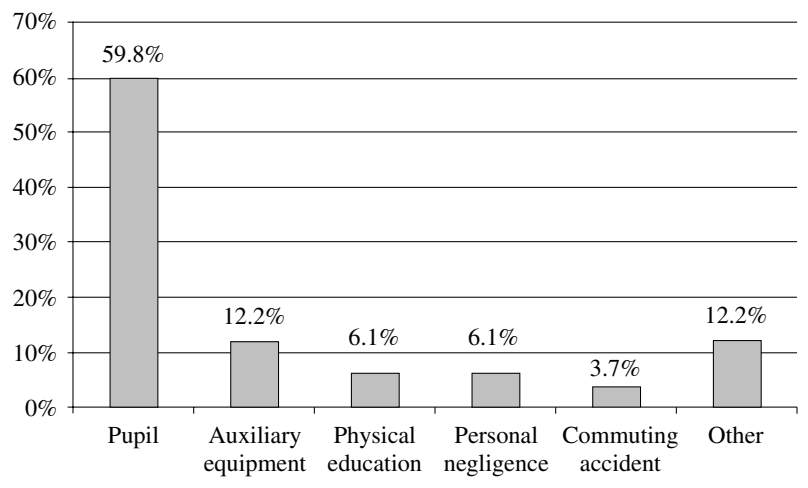

Fig. 3. Cause of injury ( $n=82$ causes; multiple answers allowed).

the previous 12 months.

\section{Implications of the findings}

We found a 12-month injury prevalence of $16.9 \%$ in our sample. In a recent German study, the one-year prevalence of injuries for nurses working in acute care hospitals was considerably higher, with $31.7 \%$ reporting an accident $(n=874 ; 2002)^{9)}$. However, since that study explicitly included needle-stick injuries, which cannot occur at the special schools included in our analyses, the differences can in part be explained by the different case definitions used. In the GEDA study, which is considered representative for the general German working population $(n=13,960)$, total 12 -month prevalences of $10.3 \%$ ( $7.6 \%$ women), and $7.6 \%(6.1 \%$ women $)$ were found for full-time and part-time workers ${ }^{20)}$ (including only accidents requiring medical assistance), respectively. Taking into account the different prevalences for the educational staff $(20.1 \%)$ and teachers $(9.9 \%)$ in our study and the fact that $90 \%$ of our sample were women, comparison with data from the GEDA study provides slight evidence indicating that educational staff comprise a group at risk of occupational accidents and injuries, 
Table 2. Nursing-related variables, stratified by injury status $(n=390)$

\begin{tabular}{|c|c|c|c|c|c|c|}
\hline \multirow[b]{3}{*}{ Nursing-related variables } & \multicolumn{6}{|c|}{$\begin{array}{l}\text { Occupational injury/injuries in the } \\
\text { previous } 12 \text { months }\end{array}$} \\
\hline & \multirow[b]{2}{*}{ Total $(\%)$} & \multicolumn{2}{|c|}{ Yes $(n=66)$} & \multicolumn{2}{|c|}{ No $(n=324)$} & \multirow[b]{2}{*}{$p$-value ${ }^{\mathrm{b}}$} \\
\hline & & $\mathrm{n}$ & $\%$ & $\mathrm{n}$ & $\%$ & \\
\hline Carry, lift and transfer pupils ${ }^{\mathrm{a}}$ & & & & & & 0.032 \\
\hline Yes, auxiliary equipment available & $153(39.2)$ & 23 & 15.0 & 130 & 85.0 & \\
\hline Yes, auxiliary equipment not available & $151(38.7)$ & 32 & 21.2 & 119 & 78.8 & \\
\hline No & $68(17.4)$ & 5 & 7.4 & 63 & 92.7 & \\
\hline Washing pupils ${ }^{\mathrm{a}}$ & & & & & & $<0.001$ \\
\hline Yes, auxiliary equipment available & $115(29.5)$ & 30 & 26.1 & 85 & 73.9 & \\
\hline Yes, auxiliary equipment not available & $99(25.4)$ & 20 & 20.2 & 79 & 79.8 & \\
\hline No & $144(36.9)$ & 9 & 6.3 & 135 & 93.8 & \\
\hline Toilet assistance for pupils ${ }^{\mathrm{a}}$ & & & & & & 0.074 \\
\hline Yes, auxiliary equipment available & $154(39.5)$ & 27 & 17.5 & 127 & 82.5 & \\
\hline Yes, auxiliary equipment not available & $136(34.9)$ & 29 & 21.3 & 107 & 78.7 & \\
\hline No & $54(13.9)$ & 4 & 7.4 & 50 & 92.6 & \\
\hline Changing pupils' diapers ${ }^{\mathrm{a}}$ & & & & & & 0.223 \\
\hline Yes, auxiliary equipment available & $164(42.1)$ & 25 & 15.2 & 139 & 84.8 & \\
\hline Yes, auxiliary equipment not available & $101(25.9)$ & 22 & 21.8 & 79 & 78.2 & \\
\hline No & $85(21.8)$ & 11 & 12.9 & 74 & 87.1 & \\
\hline (Un-)dressing pupils & & & & & & 0.141 \\
\hline Yes & $346(88.7)$ & 62 & 17.9 & 284 & 82.1 & \\
\hline No & $44(11.3)$ & 4 & 9.1 & 40 & 90.9 & \\
\hline Administration of drugs / food to pupils & & & & & & 0.013 \\
\hline Yes & $326(83.6)$ & 62 & 19.0 & 264 & 81.0 & \\
\hline No & $64(16.4)$ & 4 & 6.3 & 60 & 93.8 & \\
\hline Catheterization & & & & & & 0.431 \\
\hline Yes & $103(26.4)$ & 20 & 19.4 & 83 & 80.6 & \\
\hline No & $287(73.6)$ & 46 & 16.0 & 241 & 84.0 & \\
\hline Physical strain due to unexpected conduct of pupils & & & & & & $<0.001$ \\
\hline Daily & $202(51.8)$ & 48 & 23.8 & 154 & 76.2 & \\
\hline Weekly & $101(25.9)$ & 13 & 12.9 & 88 & 87.1 & \\
\hline Monthly or less & $81(20.8)$ & 4 & 4.9 & 77 & 95.1 & \\
\hline
\end{tabular}

Percentages are relative to the total number of respondents per variable (row) except for those in brackets (column percentages). ${ }^{a}$ Missing values for carry, lift, and transfer pupils $(n=18)$, washing pupils $(n=32)$, toilet assistance $(n=46)$, changing pupils' diapers $(n=40)$, and physical strain $(n=6)$ are not displayed in the table 'Pearson's chisquared test.

although it has to be kept in mind that our case definition was not limited to injuries requiring medical assistance. Other international studies found a prevalence similar to ours, with a prevalence of $19.2 \%$ being reported in an American study on emergency nurses $(n=2,294 ; 2012)^{21)}$ and a prevalence of $10.1 \%$ being reported in a large Australian study on nurses in Queensland $(n=5,724 ; 2011)^{16)}$. However, although the prevalence of injuries in our sample may be in line or even lower compared with other studies on this topic, an annual injury proportion of $16.9 \%$ (almost one in five persons) is certainly too high and should lead to establishment of countermeasures.

Regarding personal characteristics, only profession was significantly associated with occupational injury in bivariate analysis. The 12-month injury prevalence for educational staff $(20.1 \%)$ was higher compared with that for teachers $(9.9 \%)$, although no such association was observed after controlling for other variables in the multivariable model. An explanation for this finding could be that educational staff are more often involved in nursing tasks that are for them risk 
Table 3. Multivariable logistic regression analysis of factors that influenced whether $(=1)$ or not $(=0)$ participants suffered an occupational injury in the previous 12 months $(\mathrm{n}=390)$

\begin{tabular}{|c|c|c|c|}
\hline & \multicolumn{3}{|c|}{$\begin{array}{c}\text { Multivariable logistic regression } \\
\text { analysis }(n=390)\end{array}$} \\
\hline & $\mathrm{aOR}$ & \multicolumn{2}{|c|}{$95 \% \mathrm{CI}$} \\
\hline \multicolumn{4}{|l|}{ Personal characteristics } \\
\hline Age (continuous) & 1.02 & 0.99 & 1.05 \\
\hline \multicolumn{4}{|l|}{ Sex } \\
\hline Male & 1.53 & 0.65 & 3.61 \\
\hline Female & \multicolumn{3}{|c|}{ Reference category } \\
\hline \multicolumn{4}{|l|}{ Profession } \\
\hline Educational staff & 1.57 & 0.77 & 3.22 \\
\hline Teacher & \multicolumn{3}{|c|}{ Reference category } \\
\hline \multicolumn{4}{|l|}{ Nursing-related variables ${ }^{\mathrm{a}}$} \\
\hline \multicolumn{4}{|l|}{ Carry, lift, and transfer pupils } \\
\hline Yes, auxiliary equipment available & 0.78 & 0.25 & 2.47 \\
\hline Yes, auxiliary equipment not available & 1.51 & 0.48 & 4.73 \\
\hline No & \multicolumn{3}{|c|}{ Reference category } \\
\hline \multicolumn{4}{|l|}{ Washing pupils } \\
\hline Yes, auxiliary equipment available & 3.93 & 1.66 & 9.31 \\
\hline Yes, auxiliary equipment not available & 2.14 & 0.86 & 5.29 \\
\hline No & \multicolumn{3}{|c|}{ Reference category } \\
\hline \multicolumn{4}{|l|}{ Administration of drugs / food to pupils } \\
\hline Yes & 1.50 & 0.46 & 4.84 \\
\hline No & \multicolumn{3}{|c|}{ Reference category } \\
\hline \multicolumn{4}{|c|}{ Physical strain due to unexpected conduct of pupils } \\
\hline Daily & 3.70 & 1.20 & 11.37 \\
\hline Weekly & 2.45 & 0.73 & 8.20 \\
\hline Monthly or less & \multicolumn{3}{|c|}{ Reference category } \\
\hline
\end{tabular}

OR, adjusted odds ratio - mutually adjusted for all variables in the model; 95\% CI, 95\% confidence interval. adjusted odds ratios and corresponding 95\% confidence intervals for the missing-indicator variables have been omitted in the table.

factors for occupational injuries. Apart from this, although statistically not significant, a certain gradient could be observed with respect to BMI, with obese people having a higher 12-month injury prevalence $(25.0 \%)$ compared with respondents who were overweight $(21.1 \%)$ or normal weight $(14.2 \%)$. BMI as a risk factor for the occurrence ${ }^{22,23)}$ and severity ${ }^{24)}$ of occupational injuries has already been reported in previous studies, and it underlines the need to support a healthy lifestyle. The implementation of workplace health programs including the provision of healthy foods and the organization of joint sports activities could be helpful in this regard.

Surprisingly, age, and duration of professional activity in the current workplace were not associated with injury status, although recent studies have shown that people with less workplace experience suffer from more accidents ${ }^{9}$ and that younger employees are more at risk of suffering an accident (e.g., due to risky behavior) than older colleagues ${ }^{20,25)}$. It can be speculated that at special schools, risky working tasks are more equally distributed between age groups and difficult tasks are passed to more experienced employees.

The vast majority of staff at special schools (educational staff as well as teachers) are involved in some type of nursing activity. Tasks requiring heavy physical work, like carrying, lifting, and transferring pupils, for example, are carried out by almost $80 \%$ of staff. The 12-month injury prevalence was always higher when participants were involved in some kind of nursing activity (independent of auxiliary equip- 
ment being available or not). Significant associations with occupational injuries in bivariate analyses could be observed for lifting/transferring of pupils, washing pupils, and administration of drugs/food to pupils. Numerous studies have come to the conclusion that nursing tasks requiring heavy physical efforts including manual handling or transfer of patients are an important risk factor of occupational injuries (mainly affecting the back) in nurses, including those of Andersen et al., Engkvist et al., and Pompeii et al. ${ }^{10,13,26)}$.

Furthermore, all nursing tasks require close contact between staff and pupils, making employees vulnerable to sudden unintentional violence or uncontrolled movements by handicapped pupils. This reasoning is further reinforced by the fact that there was a significant association between injury prevalence and the frequency of strain due to unexpected conduct of pupils. The injury prevalence for teachers and educational staff who suffered from daily physical strain (23.8\%) was considerably higher compared with staff, who suffered from physical strain only monthly or less $(4.9 \%)$. Furthermore, almost two-thirds of the respondents $(59.8 \%)$ directly mentioned pupils as being the major cause behind an injury.

In order to prevent accidents during nursing activities, teachers and educational staff must be protected against both overexertion due to heavy physical work and aggression of multiple and severely handicapped pupils. According to the international literature on injuries and accidents in nurses, it is known that multifaceted approaches including sufficient supply of auxiliary equipment in all facilities along with regular training and monitoring of staff on the proper use of these devices, workplace safety programs, and interventions aimed at health promotion can help to reduce injury risk ${ }^{11,27,28)}$. As shown in Table 2, auxiliary equipment for different nursing tasks is often not available at special schools. This underlines the need to allocate sufficient resources so that sufficient devices can be provided. Furthermore, it was shown that even when auxiliary equipment was available, the injury prevalence for different nursing tasks was only slightly reduced, that is, by about 5-6 percentage points. When washing pupils, the injury prevalence when auxiliary equipment was available $(26.1 \%)$ was even higher than when it was not $(20.2 \%)$. This finding remained significant in the multivariable analysis, which showed that washing pupils with available auxiliary equipment was a significant factor that influenced the occurrence of occupational injuries. This finding, along with the fact that one in ten injuries were actually caused by assistive devices, underlines the need for regular schooling and training on the use of these devices, as well as the need for maintenance measures to ensure that technical equipment works properly.

\section{Limitations}

The results of this study are limited in several respects. Although the response rate of about $60 \%$ is comparable to other studies for this type of school ${ }^{29,30)}$, serious selection bias due to nonresponse of a substantial number of teachers/educational staff cannot be dismissed easily. A further limitation consists of the possibility of recall bias due to the retrospective design of our study. Respondents were classified as having suffered from an injury based solely upon their subjective memories. This could not be verified by objective criteria such as an official accident report. Furthermore, it is not known if the type of injury stated in the questionnaire would accord with an objective diagnosis made by a physician.

Conflicts of interest: The authors declare that they have no conflicts of interest.

Acknowledgments: The study was funded by the Unfallkasse Rheinland-Pfalz.

\section{References}

1) Bundesanstalt für Arbeitsschutz und Arbeitsmedizin (ed.). Sicherheit und Gesundheit bei der Arbeit 2012. Unfallverhütungsbericht Arbeit. [Online]. 2012 [cited 2014 Sept 9]; Available from: URL: http://www.baua.de/de/Informationen-fuer-die-Praxis/ Statistiken/Suga/Suga.html (in German).

2) van den Broek $K$, de Greef $M$, van der Heyden S, Kuhl K, Schmitz-Felten E. Die Ergebnisse der benOSH-Studie. Sozioökonomische Kosten von arbeitsbedingten Unfällen und Erkrankungen. [Online]. 2011 [cited 2014 Sept 9]; Available from: URL: http://www.kooperationsstelle-hh.de/ wp-content/uploads/benosh_publication_111017_d. pdf (in German).

3) Goossens L, Verrelst R, Cardon G, De Clercq D. Sports injuries in physical education teacher education students. Scandinavian journal of medicine \& science in sports [published online ahead of print February 5, 2013]. (doi: 10.1111/sms.12054).

4) Kovac M, Leskosek B, Hadzic V, Jurak G. Injuries among Slovenian physical education teachers: a cross-sectional study. International journal of occupational safety and ergonomics: JOSE 2013; 19: 87-95.

5) Lemoyne J, Laurencelle L, Lirette M, Trudeau F. Occupational health problems and injuries among Quebec's physical educators. Appl Ergon 2007; 38: 625-34.

6) Alamgir H, Yu S, Chavoshi N, Ngan K. Occupational injury among full-time, part-time and casual health care workers. Occup Med (Lond) 
2008; 58: 348-54.

7) Fuortes LJ, Shi Y, Zhang M, Zwerling C, Schootman M. Epidemiology of back injury in university hospital nurses from review of workers' compensation records and a case-control survey. J Occup Med 1994; 36: 1022-6.

8) Rodriguez-Acosta RL, Richardson DB, Lipscomb $\mathrm{HJ}$, et al. Occupational injuries among aides and nurses in acute care. Am J Ind Med 2009; 52: 953-64.

9) Nolting HD, Berger J, Schiffhorst G, Genz HO, Kordt M. [Job strain as a risk factor for occupational accidents among hospital nursing staff]. Gesundheitswesen 2002; 64: 25-32 (in Germany).

10) Andersen LL, Burdorf A, Fallentin N, et al. Patient transfers and assistive devices: prospective cohort study on the risk for occupational back injury among healthcare workers. Scand J Work Environ Health 2014; 40: 74-81.

11) Retsas A, Pinikahana J. Manual handling activities and injuries among nurses: an Australian hospital study. J Adv Nurs 2000; 31: 875-83.

12) Pompeii LA, Lipscomb HJ, Dement JM. Surveillance of musculoskeletal injuries and disorders in a diverse cohort of workers at a tertiary care medical center. Am J Ind Med 2008; 51: 344-56.

13) Engkvist IL, Hagberg M, Hjelm EW, Menckel E, Ekenvall L. The accident process preceding overexertion back injuries in nursing personnel. PROSA study group. Scand J Work Environ Health 1998; 24: 367-75.

14) Schoenfisch AL, Lipscomb HJ, Pompeii LA, Myers DJ, Dement JM. Musculoskeletal injuries among hospital patient care staff before and after implementation of patient lift and transfer equipment. Scand J Work Environ Health 2013; 39: 27-36.

15) Verbeek JH, Martimo KP, Karppinen J, Kuijer PP, Viikari-Juntura E, Takala EP. Manual material handling advice and assistive devices for preventing and treating back pain in workers. The Cochrane Database of Systematic Reviews 2011: CD005958.

16) Vecchio N, Scuffham PA, Hilton MF, Whiteford HA. Work-related injury in the nursing profession: an investigation of modifiable factors. J Adv Nurs 2011; 67: 1067-78.

17) Sherehiy B, Karwowski W, Marek T. Relationship between risk factors and musculoskeletal disorders in the nursing profession: a systematic review. Occup Ergon 2004; 4: 241-79.

18) Claus M, Kimbel R, Spahn D, Dudenhoffer S, Rose $\mathrm{DM}$, Letzel S. Prevalence and influencing factors of chronic back pain among staff at special schools with multiple and severely handicapped children in Germany: results of a cross-sectional study. BMC Musculoskelet Disord 2014; 15: 55.
19) Robert Koch-Institute (ed.). Beiträge zur Gesundhe itsberichterstattung des Bundes. Daten und Fakten: Ergebnisse der Studie "Gesundheit in Deutschland aktuell 2010”. [Online]. 2010 [cited 2014 Sept 9]; Available from: URL: http://edoc.rki.de/documents/ rki_fv/remDCCtjOJxI/PDF/21TgKGZEOWNCY.pdf (in German).

20) Robert Koch-Institute (ed.). Beiträge zur Gesundheit sberichterstattung des Bundes. Das Unfallgeschehen bei Erwachsenen in Deutschland. Ergebnisse des Unfallmoduls der Befragung „Gesundheit in Deutschland aktuell 2010“. [Online]. 2010 [cited 2014 Sept 9]; Available from: URL: http://edoc. rki.de/documents/rki_fv/re4CBMHqMjwf2/ PDF/213Q4vHuL1F6w.pdf (in German).

21) Perhats $C$, Keough V, Fogarty J, et al. Non-violencerelated workplace injuries among emergency nurses in the United States: implications for improving safe practice, safe care. J Emerg Nurs 2012; 38: 541-8.

22) Humphreys S. Obesity in patients and nurses increases the nurse's risk of injury lifting patients. Bariatr Nurs Surg Patient Care 2007; 2: 3-6.

23) Ostbye T, Dement JM, Krause KM. Obesity and workers' compensation: results from the Duke Health and Safety Surveillance System. Archives of Internal Medicine 2007; 167: 766-73.

24) Garrett B, Singiser D, Banks SM. Back injuries among nursing personnel: the relationship of personal characteristics, risk factors, and nursing practices. AAOHN J 1992; 40: 510-6.

25) Destatis. Gesundheitsrisiken am Arbeitsplatz. [Online]. 2009 [cited 2014 Sept 9]; Available from: URL: https://www.destatis.de/DE/ Publikationen/STATmagazin/Arbeitsmarkt/2009_09/ Arbeitsmarkt2009_09.html (in German).

26) Pompeii LA, Lipscomb HJ, Schoenfisch AL, Dement JM. Musculoskeletal injuries resulting from patient handling tasks among hospital workers. Am J Ind Med 2009; 52: 571-8.

27) Engkvist IL. Evaluation of an intervention comprising a no lifting policy in Australian hospitals. Appl Ergon 2006; 37: 141-8.

28) Dawson AP, McLennan SN, Schiller SD, Jull GA, Hodges PW, Stewart S. Interventions to prevent back pain and back injury in nurses: a systematic review. Occup Environ Med 2007; 64: 642-50.

29) Muto S, Muto T, Seo A, Yoshida T, Taoda K, Watanabe M. Prevalence of and risk factors for low back pain among staffs in schools for physically and mentally handicapped children. Ind Health 2006; 44: 123-7.

30) Embich JL. The relationship of secondary special educationa teachers' roles and factors that lead to professional burnout. Teacher Education and Special Education 2001; 24: 58-69. 